\title{
La noología realista de Xavier Zubiri
}

The realistic noology of Xavier Zubiri

\author{
Juan Antonio Nicolás \\ Catedrático de Universidad, Departamento de Filosofía II, Universidad de Granada \\ jnicolas@ugr.es
}

Raúl Linares Peralta

Universidad de Granada (España)

raullinares@correo.ugr.es

\author{
ATEÍSMO, CREENCIA Y SENTIDO. HOMENAJE A JUAN ANTONIO ESTRADA \\ MONOGRÁFICO COORDINADO POR REMEDIOS ÁVILA Y MIGUEL MORENO
}

\begin{abstract}
RESUMEN
La cuestión sobre el realismo de Zubiri ha suscitado mucho interés y controversia entre sus estudiosos en las últimas décadas. Su filosofía ha dado pie a diversas interpretaciones, hasta el punto de llegar a ser, en algunos puntos, contradictorias entre sí. Los debates entre estas interpretaciones siguen vigentes en la actualidad. Ante tal problemática, el presente artículo se plantea el objetivo principal de determinar en qué sentido la filosofía de Zubiri puede ser considerada realista. Para la consecución de tal objetivo se reconstruirán sistemáticamente las principales divergencias interpretativas sobre el realismo de Zubiri, sintetizando los argumentos más relevantes y sometiéndolos a valoración crítica. A partir de los resultados obtenidos por estos análisis, se ofrecerá como propuesta una interpretación noológico-realista con el fin de revisar e integrar propuestas anteriores.
\end{abstract}

\section{ABSTRACT}

The question of Zubiri's realism has aroused much interest and controversy among his scholars in recent decades. His philosophy has given rise to various interpretations, to the point of being, at some points, contradictory to each other. The debates between these interpretations are still alive today. In view of this problem, the main objective of this article is to determine in what sense Zubiri's philosophy can be conisdered realist. In order to achieve this goal, the main interpretative divergences on Zubiri's realism will be sistematically reconstructed, synthesizing the most relevant arguments and submitting them to critical evaluation. Of the results obtained from these critical analyses, a noological-realist interpretation will be offered as a proposal in order to review and integrate previous proposals.

PALABRAS CLAVE

realism | idealism | Zubiri | noología | interpretación

KEYWORDS

realism | idealism | Zubiri | noology | interpretation

\section{Introducción}

Xavier Zubiri ha dejado como legado una rica filosofía sistemática capaz de reconstruir buena parte de la historia de la filosofía desde sus cimientos. Esta virtud, que permite reinterpretar críticamente otras muchas teorías filosóficas desde sus nociones propias, ha producido, no obstante, problemas interpretativos internos aún vigentes entre sus discípulos e investigadores. La sistematicidad exige de suyo rigor conceptual, lo cual se hace más que patente en sus dos obras fundamentales: Sobre la esencia y la trilogía Inteligencia sentiente. Si bien estas dos obras pertenecen, debido a matices en su contenido y por el tiempo transcurrido, a fases distintas del autor (Gracia 2017), el problema a tratar de fondo es el mismo: el estudio de la experiencia originaria de la filosofía, a saber, la experiencia de la realidad. Para Zubiri (1984: 47), "la filosofía no es filosofía ni de la objetividad ni del ente, no es fenomenología ni ontología, sino que es filosofía de lo real en cuanto real, es metafísica". En este sentido, sus dos obras clave forman parte de lo que él considera "metafísica" o filosofía primera en tanto que ambas abordan qué sea realidad y cuál es el modo específicamente humano de estar y saber de ella.

Sin embargo, ¿son conciliables las definiciones y los análisis que se dan de la noción de "realidad" en una y otra obra, cuando Zubiri parece centrarse en aspectos y perspectivas netamente diferenciados? A primera vista, en Sobre la esencia se centra en la independencia y alteridad de la "cosa-realidad", que 
queda definida como "todo y solo aquello que actúa sobre las demás cosas o sobre sí mismo en virtud, formalmente, de las notas que posee" (Zubiri 1962: 104). En cambio, en Inteligencia sentiente se centra en la mutua dependencia entre realidad y saber, como dos momentos de un mismo acto: el acto de aprehensión. Realidad se entiende aquí como "mera formalidad de realidad", es decir: "no se trata de cosa real en la acepción de cosa allende la aprehensión, sino de lo aprehendido mismo en la aprehensión pero en cuanto está aprehendido como algo que es 'en propio"' (Zubiri 1980: 12). Sean análisis convergentes o no, lo cierto es que representan dos puntos de vista diferentes desde los que afrontar el análisis de lo real. Aun siendo conciliables, lo que esta divergencia de perspectivas pone sobre la mesa es la posibilidad de dos interpretaciones posibles del conjunto: una, que entiende que el núcleo del pensamiento zubiriano está representado por Sobre la esencia y sus cursos adyacentes, con lo que Inteligencia sentiente debería entenderse a partir de aquélla; otra, que entiende que "el método noológico que Zubiri exponía en esos volúmenes [en Inteligencia sentiente] obligaba a repensar la mayoría de los conceptos de Sobre la esencia" (Gracia 1986: III). Estas dos posibles reconstrucciones del pensamiento zubiriano han sido defendidas, como veremos, por sus discípulos e investigadores hasta hoy.

En estos debates una de las cuestiones de fondo que se discuten es si Zubiri puede ser adscrito a las filas del realismo filosófico, y si la respuesta es afirmativa, en qué sentido exactamente puede hacerse. Esta cuestión es polémica al menos por dos motivos. En primer lugar, porque el propio Zubiri adopta una posición muy crítica con diversas versiones del realismo. En segundo lugar, porque entre los investigadores e intérpretes no hay un acuerdo acerca de esta cuestión; antes bien, hay posiciones claramente encontradas. De la primera cuestión nos hemos ocupado en (Nicolás 2021). Esta segunda problemática es el objeto del presente análisis.

El punto de discusión es en qué sentido interpretar el momento de independencia del "de suyo", que puede llevar a entender la realidad bien como formalidad y contenido (así parece exponerse en Sobre la esencia, sobre todo al conferir sustantividad a la cosa-realidad) (Gracia 2017: 152-154), bien como mero carácter formal de lo aprehendido (como advierte ya en algunos pasajes de Sobre la esencia, que quedan reafirmados rotundamente en Inteligencia sentiente al hacer consustancial la realidad al hecho de darse en la aprehensión). Si en Sobre la esencia Zubiri aborda la cuestión filosóficamente esencial de qué es realidad, en Inteligencia sentiente abordaría esta misma cuestión bajo la formulación de cómo estamos y cómo sabemos acerca de lo real. En este cambio de perspectiva lo que está en juego no es simplemente la importancia relativa de cada obra. Está en juego definir la compleja noción de realidad y su interrelación con el ser humano.

Esta cuestión, aparentemente sencilla desde el punto de vista histórico-crítico, sigue generando nuevas discusiones y nuevas respuestas pasados ya 40 años desde la publicación de la trilogía. Se siguen planteando tanto "sospechas de rasgos idealistas" como nuevas formulaciones de la peculiar versión del realismo zubiriano. Una muestra de ello es que en el Seminario de Investigación Xavier Zubiri, a raíz de ponencias como la de Ángel González (2020; sesión de octubre de ese año) en la que saca a relucir el debate con Ellacuría, se discute todavía cómo calificar en este punto la filosofía zubiriana. La pretensión de esta investigación es presentar las divergencias interpretativas sobre el realismo de Zubiri y explorar una de las posibles vías de resolución.

\section{Divergencias interpretativas}

El estado de la cuestión es el siguiente: por un lado, es innegable que la filosofía zubiriana tiene una impronta realista o, más aún, que es un proyecto fundamentalmente realista. De hecho, podría llegar a entenderse toda su trayectoria intelectual como una sucesión de distintas formas de realismo (Gracia 2017: 64-162). Efectivamente, ya desde 1942 Zubiri (1987: 147-148) entiende, a raíz de la experiencia originaria griega, que "toda filosofía tiene a su base, como supuesto suyo, una cierta experiencia. (...) La experiencia es, en este sentido, el lugar natural de la realidad". En su obra encontramos referencias constantes a la realidad, entendida como sustrato profundo (en el sentido de formalmente anterior) en el que estamos instalados. Y, más aún, el rasgo definitorio del ser humano consiste en ser animal de realidades. El conjunto de estas nociones articula en las obras de Zubiri un proyecto clara y originalmente realista. Por otro lado, sin embargo, no es sostenible defender que su filosofía sea un realismo en sentido convencional: en toda su trayectoria intelectual Zubiri no ha hecho alusión al realismo más que para criticarlo o para distanciarse de él. Desde un primer momento, por influencia fenomenológica, ha situado 
su filosofía en un nivel más radical, previo al de las teorías, con lo que cualquier teoría realista históricamente desarrollada será considerada, como poco, insuficiente. Ese nivel más radical se halla en la mera descripción del acto intelectivo, único hecho del que la inteligencia humana puede partir. En esto consiste la noología de Inteligencia sentiente. Si este es el punto de partida, ¿en qué sentido puede ser considerado un realismo? En tal tesitura se han dado diversas interpretaciones: unas, que atisban en la noología zubiriana cierto giro o fundamentación idealista; otras, que mantienen que cierto tipo de realismo sigue vigente caracterizado de un modo peculiar. Se analizarán sumariamente estas interpretaciones, exponiendo sus argumentos principales y sometiéndolas a valoración crítica con el objeto de ofrecer una visión sistemática (aunque no exhaustiva) de la problemática interpretativa sobre el realismo de Zubiri.

\subsection{Limitaciones de las interpretaciones idealistas \\ 2.1.1. Las sospechas idealistas de Ellacuría, el realismo de fundación idealista de Wessell y el anti-realismo de Ángel González}

Ellacuría encuentra en Zubiri una metafísica alternativa a la de la modernidad. Por su situación histórica y vital, para Ellacuría era necesario desarrollar una filosofía práctica capaz de responder a los problemas acuciantes de América Latina. Tal filosofía la desarrollaría, a partir de Sobre la esencia y cursos en los que Zubiri analiza la materia, como una forma de realismo materialista dinámico y abierto:

"Para mí el pensamiento de Zubiri es un pensamiento realista, y por lo tanto no idealista; en segundo lugar, es un pensamiento materialista, y por lo tanto no espiritualista; en tercer lugar, es un pensamiento dinámico, histórico, y por lo tanto no estático; y finalmente, es un realismo materialista dinámico abierto. Yo entiendo, he sostenido, que hay un materialismo histórico desde la perspectiva de Zubiri que, al ser abierto, nos da a nosotros una base de sustentación de la teología de la liberación" (1).

Con tales pretensiones, las nociones metafísicas fundamentales de Sobre la esencia eran muy aprovechables. El punto de apoyo de la continuación de la filosofía zubiriana que lleva a cabo Ellacuría, a saber, dotar de realidad a la historia y la sociedad tal y como había hecho Zubiri con la "cosa-realidad", sería el concepto de "sustantividad" expuesto en Sobre la esencia. Sin embargo, con Inteligencia sentiente la "sustantividad" pasa a un segundo plano, dando prioridad ahora a la noción "actualidad". Ante este cambio, el problema que encuentra Ellacuría, tal y como lo expresó en el Seminario Xavier Zubiri de 1978 (2)), era el siguiente: hay una diferencia fundamental entre el concepto de realidad entendido como formalidad y entendido como cosa real misma que puede dar lugar a graves equívocos. Inteligencia sentiente es una teoría del conocimiento $\mathrm{y}$, como tal, expone el proceso por el cual el ser humano puede llegar a saber algo de la realidad. El equívoco que haría recaer en el idealismo consistiría en considerar que en la descripción de este proceso (gnoseológico, epistemológico) se está describiendo cómo sea la cosa real misma. Es decir, el error estaría en confundir la descripción del fundamento de la intelección de la realidad con la descripción del fundamento de la realidad. Para Ellacuría, por tanto, de Inteligencia sentiente no puede -lo no debería, so pena de caer en cierto idealismo- extraerse una metafísica de la realidad. Es por esto por lo que entiende que hacer primar la noología lleva a una lectura poco realista, subrepticiamente criticista, de la filosofía de Zubiri. Ellacuría (1990: 27-29) sospecha que desde la noología existe el peligro de recaer en el principio cartesiano de que el conocimiento es, en primer lugar, conocimiento de ideas. Y sospecha también que las realidades allende la aprehensión acaben siendo reducidas a objetos para un sujeto. Siendo así, ¿qué sentido tendría la estructura entitativa propia de lo real analizada en Sobre la esencia? ¿Dónde quedaría la problemática acerca de la constitución de las cosas reales en tanto que reales? Con tales cuestiones planteadas la lectura de Ellacuría abre la sospecha de que sea posible una interpretación idealista de la noología de Zubiri.

Esa posibilidad abierta acabaría por dar lugar a una interpretación, ahora sí, explícitamente idealista defendida por Leonard P. Wessell. La original propuesta de este autor parte de la necesidad interpretativa de examinar el nivel del lenguaje. Sitúa, por tanto, las coordenadas interpretativas en un nivel semántico cuyo punto de partida es el análisis de conceptos fundamentales en la filosofía de Zubiri (Wessell 1999: 27). El concepto en que centra tal análisis es el de "algo" por ser un término utilizado por Zubiri en diversos sentidos para definir categorías centrales de su pensamiento, término que habían pasado por alto sus intérpretes anteriores. Tal concepto se convierte, según Wessell (1999: 30), en el “'andamio' semántico que une o, mejor, agrupa la multiplicidad de los elementos léxico-semánticos en una totalidad 
semánticamente campal". Efectivamente, Zubiri define la realidad como algo de suyo, de modo que tanto el significado de lo que sea "realidad" como el significado de lo que sea el "de suyo" penden de qué signifique el "algo", de la semántica de la "algoeidad". La tesis a demostrar, que marcaría la interpretación sobre Zubiri, es que el "de suyo" es también "algo", con lo que resulta necesario definir qué sea ese "algo". De lo contrario, el significado del "de suyo" quedaría vacío y, por ende, la supuesta sistematicidad del pensamiento zubiriano se pondría en cuestión.

Para Wessell (1999: 36), la idea de Zubiri (1980: 147) según la cual "las cosas reales del mundo no tienen por qué estar presentes en cuanto tales a la intelección" es una "tesis quintaesencialmente realista", asumiendo que ello significa que la realidad es independiente de la intelección. Con afirmaciones como estas, Zubiri cae en asumir que "el 'de suyo' es también allende cualquier intelección, es decir, como algo fuera de la intelección" (Wessell 1999: 36). Pero he aquí el punto en el que la tesis realista de Zubiri requiere de una base idealista: el "algo" al que hace alusión solo tiene algún sentido en tanto que se da aquende la intelección, pues solo adquiere un significado en cuanto discernimiento intelectivo, por y para una conciencia (Wessell 1999: 39-42). En conclusión, y esta es la clave de la interpretación de Wessell (1999: 44), "el realismo radical de Zubiri presupone, por lo menos, un 'idealismo conceptual' o no se refiere a nada". Esta es su paradójica propuesta, la cual pone sobre la mesa, 15 años después de las advertencias de Ellacuría, que de facto es posible una interpretación idealista de la filosofía de Zubiri.

En la actualidad se siguen presentando propuestas expresamente reticentes a considerar que Zubiri sea un pensador realista. La muestra más clara de ello es la ponencia de Ángel González en la sesión del Seminario de Investigación Xavier Zubiri del 2 de octubre de 2020 titulada "¿Realismo zubiriano? A propósito de un diálogo entre Ignacio Ellacuría y Xavier Zubiri”. Aquí Ángel González centró su análisis en los aspectos por los que la filosofía de Zubiri debe considerarse exclusivamente como una fenomenología de la actualidad, superadora de cualquier forma de realismo. Su postura, que extrae de la discusión entre Zubiri y Ellacuría a la que hemos hecho ya alusión, parte de que en Inteligencia sentiente solo se habla de las cosas en mi aprehensión, en un plano de mera descripción fenomenológica de lo que queda presente en el acto intelectivo. Por tanto, discutir si las cosas son (construidas) por mi aprehensión o si son cosas (que existen) allende mi aprehensión no son más que teorías. De hecho, son las teorías idealista y realista, respectivamente, a las que criticaba Zubiri sin dejar lugar a dudas. El problema interpretativo procede, según Ángel González, de la misma ambigüedad del lenguaje zubiriano, quien tiene que emplear términos muy cargados teóricamente. El ejemplo más claro es el del prius, a partir del cual se explica que "lo real es algo anterior a su actualización misma en la intelección sentiente: toda actualidad es 'de' lo real" (Zubiri 1980: 160). Pero Ángel González argumenta que la anterioridad en ningún caso puede entenderse cronológicamente, pues ello llevaría a considerar que existen dos zonas de realidad: una allende la aprehensión, y otra aquende la aprehensión. Y esto último es inaceptable desde Zubiri si no se quiere caer de nuevo en una teoría realista cuya ingenuidad consiste precisamente en presuponer la existencia de cosas allende la aprehensión. Si se acepta que no puede haber dos zonas de realidad desde la filosofía de Zubiri, no se puede aceptar que se denomine "realista" su filosofía en ningún sentido.

La lectura fenomenológica que Ángel González hace de Zubiri ciertamente no es una interpretación idealista sensu stricto. De hecho, él mismo advierte que Zubiri salvaguarda la razón filosófica de la crisis de nuestro tiempo precisamente por recuperar la realidad que se había perdido entre los laberintos de la subjetividad de la filosofía moderna y de la fenomenología husserliana (González 2015: 351). Pero esta recuperación de la realidad se da únicamente en su estar presente en una inteligencia, es decir: en su momento de actualidad como esencia del acto intelectivo. La reducción a la mera descripción del acto intelectivo supone, para Ángel González, la superación de cualquier forma de realismo en tanto que todo de suyo y toda alteridad son momentos presentes en la aprehensión (González 2015: 352). Con ello, puede atribuirse a Ángel González un anti-realismo interpretativo que reproduce, al menos en parte, las sospechas de idealismo de las que advertía Ellacuría.

\subsubsection{Valoración y crítica de las interpretaciones idealistas}

Las sospechas que Ellacuría vertía sobre Inteligencia sentiente fueron, son y serán una fuente argumental muy fructífera para precisar los fundamentos de la filosofía de Zubiri y, especialmente, para determinar el sentido del realismo que puede o no defenderse desde su filosofía. En efecto, Ellacuría llamó la atención sobre una diferencia radical que ha de tenerse siempre a la vista, a saber: la diferencia entre la realidad que hay y cómo llegamos a saber de la realidad. Y bajo tal distinción precisa que cuando 
Zubiri describe la aprehensión primordial de realidad lo que lleva a cabo es una descripción de la realidad aprehendida, no de la realidad en tanto que realidad. El matiz que cabe aportar para eludir las sospechas idealistas en este punto sería el siguiente: la realidad aprehendida primordialmente es aprehendida como realidad. $\mathrm{Y}$ justamente ese modo en que aprehendemos las cosas no permite caer de ningún modo en el criticismo del que Ellacuría advertía, pues en tanto que se impresionan las cosas como realidades nuestra intelección no puede en ningún caso construir lo que esas realidades son. No pueden ser consideradas representaciones, pues tienen rasgos formales propios que le pertenecen "de suyo". Pero para conocer ese "de suyo" de las cosas reales el ser humano debe apoyarse en el modo como se le ha dado la realidad. Zubiri (1980: 193) es bien claro al respecto: "toda metafísica de la realidad como existente y como poseedora de notas propias (lo real en tanto que real) ha de fundarse inexorablemente en la formalidad misma de realidad". La realidad, por tanto, no se entiende en Inteligencia sentiente como el conjunto de cosas reales sino como término formal de la inteligencia. Ellacuría reprochaba entonces que la trilogía no consistía más que en una teoría del conocimiento y que, por tanto, no podía dar cuenta de qué es la realidad en cuanto tal. Pues bien, cabe asumir que Inteligencia sentiente no pretende esto sino asumir humildemente las limitaciones de la inteligencia humana según se sigue del análisis de los actos intelectivos: el paso de la realidad como formalidad a lo que sean las cosas reales es un camino intelectivo que, si bien está impuesto por el modo como aprehendemos la realidad, siempre está abierto y en marcha. Pero, eso sí, la realidad es el punto de partida en el que estamos instalados y es ella misma la que nos arrastra allende la aprehensión primordial. El momento de realidad del acto intelectivo es irrenunciable: comenzar por analizar el hecho de que esté presente en nuestra aprehensión no quiere decir que esté presente por nuestra aprehensión. Y esta tesis en ningún caso podría ser sostenida desde una postura criticista-idealista.

En el caso de la interpretación de Wessell, cabe reconocer que el exhaustivo y novedoso análisis que llevó a cabo de conceptos tan relevantes en la filosofía de Zubiri resultó muy estimulante para los estudiosos, pues sacó a la luz las complejidades terminológicas de un pensamiento con pretensiones sistemáticas. Obligó, por tanto, a repensar algunas nociones y, sobre todo, a definir aquellas con las que Zubiri no había sido lo suficientemente claro. Buena muestra de ello fue la oleada de críticas y respuestas que Wessell recibió, entre las que cabe destacar la realizada por Pintor (1995a), quien rechazó frontalmente las categorías realismo-idealismo en las que situó Wessell su interpretación de Zubiri. Concluir, tal como hizo Wessell, que el realismo radical de Zubiri tiene una base idealista es, por tanto, un encierro en esos seudoproblemas que Zubiri salva remitiéndose a un ámbito previo de experiencia (el fenomenológico), anterior al de las teorías (sean realistas o idealistas). Afinando los conceptos que Wessell se propone analizar, cabe criticar de su interpretación que la noción de "de suyo" es descrita por Zubiri de modo fenomenológico. Siendo así, no puede analizarse en función del contenido de la semántica del "algo" si no se ha situado antes tal contenido en la respectiva formalidad según la cual ha quedado actualizada en una inteligencia sentiente (Gracia 2017: 154 y Conill 2018: 276). El "de suyo" no requiere de una semántica de la "algoeidad", con lo que la premisa de Wessell queda invalidada. Por tanto, queda sin justificar su pretensión de fundamentar el realismo radical de Zubiri sobre un idealismo conceptual.

En lo que respecta a la lectura de Ángel González cabe reconocer que, en tanto que remarca el carácter fenomenológico con que Zubiri analiza el acto de intelección, recuerda y deja claro un límite de la noología zubiriana: no puede afirmarse la existencia de cosas reales allende la aprehensión. Justamente esta idea es la que estaba en juego en la discusión con Ellacuría, y a la que Zubiri responde tajantemente que tal afirmación supondría una ingenuidad injustificable. De ahí procederá la crítica al realismo clásico (que será expuesta más adelante). No obstante, de ello no se sigue que la filosofía de Zubiri sea per se anti-realista, tal y como concluye Ángel González. Considerar que las únicas formas de realismo en filosofía se reducen a las teorías realistas históricamente existentes parece, al menos, una visión demasiado restrictiva y acotada de lo que pueda ser el realismo. Si la realidad, tal como la comprende Zubiri, puede ser más que la existencia efectiva de cosas reales, entonces el realismo también debería poder significar más que la mera afirmación de una zona de cosas reales. Reducir la realidad -y, por ende, el realismo- a la mera existencia efectiva es justamente caer en la ontificación de la realidad que tanto se había esforzado Zubiri en criticar. Aunque el punto de partida del análisis sea aquende la intelección, ello no obsta para que la realidad no tenga un papel tan primordial en la filosofía de Zubiri que no pueda dejar de calificarse como realista, aún cuando sea un realismo sui generis.

Aunque las sospechas o interpretaciones idealistas hayan sido minoritarias entre los estudiosos de Zubiri, resultan de interés a la hora de delimitar el marco de estudio de la noología zubiriana. Ahora bien, si bien son de ayuda porque obligan a matizar y precisar algunos aspectos importantes de la filosofía de 
Zubiri, es preciso distanciarse de ellas: Zubiri no hace en ningún sentido una filosofía idealista. Los límites de la noología son complejos, pero en modo alguno se reduce a mera teoría del conocimiento y en todo momento está imbricada la realidad.

\subsection{Dificultades y posibilidad de la interpretación realista}

\subsubsection{Crítica zubiriana de los realismos}

La interpretación realista, aunque mayoritaria, no se salva de tener que afrontar ciertas dificultades. La fundamental es que Zubiri, en todos sus escritos y cursos, no hace alusión al realismo más que para criticarlo. En qué consiste tal crítica es lo que se analizará a continuación con el fin de precisar qué sentido de realismo no conviene de ningún modo a la filosofía de Zubiri.

Zubiri sostiene, como punto de partida, una tesis fenomenológica, a saber: la filosofía debe diferenciar su ámbito de estudio de los contenidos presentados por explicaciones teóricas. El modo de cribar tales contenidos no es otro que el método fenomenológico, que permite separar las explicaciones teóricas de los datos primordiales presentes en el acto de la conciencia (en el caso de Husserl) o de la intelección (en el caso de Zubiri). Este es el modo adecuado de acercarnos a qué sean las cosas realmente. En este sentido Zubiri remite a un ámbito de experiencia previo a partir del cual rechaza tanto la presuposición injustificada de la cosa real (realismo antiguo, ingenuo) como la presunción de algo trascendente a lo que se nos presenta (realismo moderno, crítico). La crítica a estas dos formas de realismo, tal y como muestra Juan Antonio Nicolás en "La crítica a los realismos desde la noología realista zubiriana" (2021), ha sido sistemática y sostenida en el tiempo.

En cuanto al realismo antiguo, Zubiri se muestra tajante desde la década de 1920 hasta sus últimos días de vida. La crítica ha sido sistemáticamente la misma, sea cual sea el contexto en que se halle. Es interesante ver que sus primeros escritos y cursos son muy similares a los últimos en este punto: en las décadas de 1920 y 1930, Zubiri (2007: 509) deja claro que "el realismo es insostenible como punto de partida de una filosofía", y ello porque "yo no me encuentro dentro de mí con la cosa real, sino con el acto de percibirla" (Zubiri 2007: 508). Con ello se sitúa en un plano distinto de reflexión, acusando al realismo de ingenuo por la presuposición acrítica de la existencia exterior del mundo independiente de cualquier tipo de conciencia o aprehensión humana. Esto ha de ser justificado. En esta misma dirección va la crítica de 1980, cuando afirma, refiriéndose al realismo antiguo, que se sitúa "frente a una idea de realidad que consistiera en pensar que realidad es realidad en sí (...). [Pues] no se trata de ir allende lo aprehendido en la aprehensión sino del modo como lo aprehendido 'queda' en la aprehensión misma" (Zubiri 1980: 57-58). Los términos, aunque ahora más depurados, significan esencialmente lo mismo. De igual modo se refiere al realismo en las fases intermedias de su pensamiento, tal y como puede apreciarse en el curso del año 1967: "El error del realismo ingenuo estará en creer que sin mis órganos receptores el mundo tiene toda la gama de colores y cromatismos que la percepción presenta. Esto con toda seguridad, es completamente falso" (Zubiri 2005: 176), así como en el curso de 1973 cuando sostiene que "afirmar la realidad [allende la aprehensión] de las cualidades sensibles sería un inadmisible realismo ingenuo" (Zubiri 1996: 335-336). Bajo estas claves, cualquier acusación a Zubiri de ser realista en un sentido clásico es, como mínimo, improcedente. $Y$ más aún si tenemos en cuenta que junto a esta sistemática crítica no le acompaña ninguna referencia positiva alguna sobre el realismo que pudiera dar lugar a duda. De hecho, en la obra que podría fundar (y de hecho fundó) alguna que otra sospecha realista (a saber, Sobre la esencia, por los conceptos que estudia: realidad, esencia, sustantividad), no se menciona siquiera el término "realismo". Este es un detalle que no conviene olvidar.

En cuanto al realismo crítico, que Zubiri conoció de la mano de los neotomistas de la época que buscaban depurar el idealismo kantiano (Mercier y Marechal serían las figuras más paradigmáticas de la Escuela de Lovaina), ocurre algo parecido: la crítica es sistemática de principio a fin en toda su filosofía. En las décadas de 1920 y 1930, ya veía la condena al fracaso de un realismo que entendía que "el problema del conocimiento surge en la afirmación de poner en relación todo el mundo inmanente con otro de fuera. (...) No puede comenzar el conocimiento por una relación de un sujeto con un objeto" (Zubiri 2007: 513-515). Distinguir dos planos de realidad hace imposible entender el paso de la representación a la realidad, tal como le ocurre al idealismo. Por ello entiende que el realismo crítico es "realista más en sus intenciones que en otra cosa" (Zubiri 2007: 348). Esta misma idea será la que desarrolle en Naturaleza, Historia, Dios (1942) sin apenas cambiar en lo sustancial, pues considera que 
el realismo crítico es "no solamente algo insuficiente, sino más bien inútil. (...) [Por el supuesto según el cual] la existencia de un mundo 'exterior' es algo 'añadido' a la existencia del sujeto" (Zubiri 1942: 420-421). Más tarde, tras publicar Sobre la esencia, Zubiri se ve en la obligación de defenderse de aquellas acusaciones que lo situaban en sintonía con el realismo crítico, pues en el contexto cultural europeo en que fue escrita esta obra parecía ir en la línea de algunos teólogos neotomistas que depuraban la vieja metafísica pasándola por el idealismo kantiano. Nada más lejos de la intención de Zubiri. La defensa, tres años después de la publicación de Sobre la esencia, fue tajante: "los viejos realistas críticos -a mí se me ha atribuido toda clase de peregrinas etiquetas-creían que, si se aplica el principio de causalidad al decurso de las impresiones, por él llegamos a concebir la existencia del mundo real. Lo que no entiende uno es cómo con impresiones, que no son reales, haya principio de causalidad ninguno que pueda llegar a una realidad" (Zubiri 2001: 36). La crítica no deja lugar a dudas: la filosofía de Zubiri ni es ni puede ser interpretada como un realismo crítico, habida cuenta de que este parte de los mismos supuestos que el idealismo. Al aplicar la crítica al análisis de las impresiones, acaba dando un paso más que se hace patente en la última década de su vida, pues entiende que "la causalidad no parte solamente de las impresiones subjetivas de la realidad, sino que tiene que apoyarse en lo percibido mismo. Y si lo percibido es formalmente subjetivo, entonces la causalidad cae en el vacío" (Zubiri 1980: 180). Este defecto de partida hace del realismo crítico no más que una teoría insuficiente, errada, que no puede servirnos en ningún caso como filosofía primera. Cualquier duda que se pudiera generar en Sobre la esencia queda disipada en toda una trayectoria en la que no se refiere a este realismo más que para criticarlo.

\subsubsection{Posibilidad de la interpretación realista}

A la vista de las rotundas críticas a los dos tipos de realismo predominantes en la historia de la filosofía, resulta sorprendente ver en los intérpretes más reconocidos de Zubiri el término 'realismo' como modo de caracterizar su filosofía. Pues bien, nuestra intención aquí es mostrar el por qué de este hecho, aclarando en qué sentido puede ser considerada la filosofía de Zubiri como un tipo peculiar de realismo.

Zubiri se atiene en el análisis de los actos intelectivos al simple (pero complejo) hecho de cómo algo es real en la aprehensión, entendido como algo formalmente anterior a lo que sea sustantivamente. Aquí los matices son importantes: se trata de qué sea la realidad en la aprehensión y no de qué sea la realidad por la aprehensión. Frente al idealismo cartesiano, Zubiri (1980: 11) entiende que el conocimiento no puede partir de ideas que un sujeto se forma en base a los objetos que percibe o intuye, pues "lo primario del conocimiento está en ser un modo de intelección" que no puede más que analizarse por sus actos. El estudio de tales actos es en lo que consiste la noología, que se define como "investigación acerca de lo que estructural y formalmente es la inteligencia" (Zubiri 1980: 11), la cual es intrínsecamente congénere a la realidad. Este es el punto de partida ineludible. Al reconocer que la noología es análisis de los hechos de intelección, algunos de los intérpretes de Zubiri se decantaron por una lectura que entendía que la noología de Inteligencia sentiente reformulaba tesis de la filosofía anterior de Zubiri. Buena muestra de ello es la reconocida guía de lectura de Diego Gracia, Voluntad de verdad (1987), en la cual se ofrecía una lectura de la filosofía zubiriana que situaba el punto arquimédico en las claves noológicas de Inteligencia sentiente. El desarrollo de tal noología dejaba establecido que saber y realidad, en tanto que congéneres, son dos momentos de la aprehensión cuyo acto constitutivo es la aprehensión primordial de realidad. El ser humano aprehende las cosas formalmente como realidades: es un animal de realidades. O lo que es lo mismo: las cosas se actualizan en la aprehensión formalmente como realidades. Por ello, la noología zubiriana lleva irremisiblemente a una filosofía de la realidad y viceversa. En este sentido puede sostenerse que Zubiri defiende un tipo de realismo delimitado por la noología: es decir, una noología realista o un realismo noológico. Se trata de un realismo sui generis, claro está, en un ámbito distinto al de los realismos históricamente existentes en tanto que parte de una definición de realidad completamente distinta, a saber: realidad es formalidad en la aprehensión, no existencia ni ente ni objeto de conocimiento. Con lo cual queda enmarcada en un nivel, de partida, intraintelectivo.

Sin embargo, las posibilidades de interpretar a Zubiri como realista no se han reducido a esta delimitación noológica, sino que han sido adjetivadas de múltiples modos: Ferraz lo denomina realismo radical; Gómez Cambres, realismo trascendental; Hernáez, realismo sistémico; Fernández de la Mora, hiperrealismo; Garrido Zaragozá, realismo puro; Ortiz Osés, realismo físico; Basabe Martín, metafísica realista; Pérez Villamarín y Serrano Vargas, realismo filosófico; Díaz, realismo constructivo; Conill, realismo noérgico; Pintor y Monserrat, realismo zubiriano; Nicolás Marín, noología realista; Gracia, realismo de la actualidad; Sierra, reología (nuevo realismo) o realismo real, etc. (Nicolás 2021). 
Veamos cómo es posible reunir todos estos diversos tipos de realismos atribuidos a Zubiri. Todos ellos convergen en la idea del indiscutible y primordial papel de la realidad en el pensamiento zubiriano; y, habida cuenta de la multitud de intérpretes que han considerado a Zubiri como realista, se hace patente que la interpretación realista es -al menos- posible.

\section{Por un realismo transformado: noología realista}

Ante la amplia diversidad de propuestas para definir el realismo de Zubiri, surge la cuestión acerca de cuál es la que mejor precisa el sentido en que la filosofía de Zubiri puede ser considerada realista. Para responder a ello son posibles al menos dos estrategias distintas: 1) poner el foco en un elemento específico de la filosofía de Zubiri que se considera especialmente relevante y que, por tanto, es el que caracteriza su particular realismo; 2) buscar una plataforma comprehensiva de un conjunto de rasgos de modo que en su unidad caractericen el realismo de Zubiri. En los siguientes apartados se expondrán las propuestas que han tomado una "estrategia focalizada", para, a continuación, ofrecer la propuesta noológico-realista como ensayo de una "estrategia comprehensiva".

\subsection{Interpretaciones realistas via "estrategia focalizada"}

Antonio Ferraz, en una de las primeras caracterizaciones tras la publicación de la trilogía, calificó la filosofía de Zubiri como "realismo radical". Ferraz parte de una distinción primordial entre 'realidad' y "realidad-de": la una nos instala en el ámbito de la aprehensión intelectiva, referencia original de la que debemos de partir siempre; la otra, que nos lleva a lo que sea tal realidad en tanto realidad, en sí misma, como investigación racional a la que el "de suyo" de lo aprehendido nos lleva. En su lectura de Zubiri pone el foco de atención en qué sea la realidad no ya entendida como el término formal de la intelección sino como algo que puede ser estudiado por sí mismo. Claro está, reconoce que no se puede salir de la inteligencia, pero lo real (la "realidad-de") pasaría a ser estudiado en un primer plano (Ferraz 1987: 117-118). La distinción tan tajante entre estos dos modos de consideración de la realidad le permite dividir en su obra dos partes diferenciadas: la intelección, dedicada a explicar las nociones clave de Inteligencia sentiente; y la realidad, dedicada a reconstruir la metafísica de la realidad zubiriana de Sobre la esencia y algunos cursos adyacentes a la luz de las novedades de Inteligencia y razón, el tercer tomo de la trilogía. Lo "radical" del "realismo" de Zubiri que Ferraz propone consistiría entonces en que lo real aprehendido nos lleva a una investigación metafísica de lo que la realidad sea por sí misma. Abre las puertas, por consiguiente, a que de la filosofía de Zubiri se extraiga una metafísica de la realidad y, por ende, una filosofía dedicada al análisis de sustantividades, esencias y fundamentos racionales. Es por ello por lo que los posteriores estudios de Ferraz (2011) han ido exclusivamente dirigidos a cuestiones sobre filosofía de la ciencia o de la naturaleza en los que aplica las categorías zubirianas a nociones científicas muy concretas.

Por su parte, Antonio Pintor, en términos muy generales, define el pensamiento maduro de Zubiri como una "filosofía de la realidad", entendiendo por realidad "la determinación primaria y fundante para todo nuestro saber y todas nuestras acciones" (Pintor 1995b: 109). Si bien la delimitación puede resultar un tanto inconcreta, la definición de realidad expresa que la interpretación es marcadamente realista, pese a la cautela del autor para usar el término "realismo" referido a la filosofía de Zubiri. Pintor solo menciona el realismo para criticarlo (salvo en 1994: 107, donde hipotéticamente habla de "realismo zubiriano"). Se hace aún más patente el realismo de esta lectura si se atiende al papel primordial que reserva al carácter de prius de la realidad con respecto a su actualización intelectiva. Esta anterioridad, que es formal, muestra para Pintor una prioridad ineludible de la realidad sobre la intelección: "El prius, aunque aparezca dado en aprehensión, apunta a una anterioridad de lo dado respecto a su aprehensión y, por tanto, el canon de la intelección es ese prius" (Pintor 2006: 124). Y, en tanto que es su canon, llega a asumir que la realidad no puede ser solo en la aprehensión, pues si así fuera el momento de "hacia", de trascendentalidad, quedaría agotado en el orden de la aprehensión (Pintor 2006: 123). Esta prioridad de lo real, para más señas, se hace patente en el carácter noérgico de la intelección, que marca la modalización interna del inteligir. De ahí que, a juicio de Pintor, el término de "noología" sea una denominación mucho más pobre y vaga (Pintor 2006: 124), pues no daría buena cuenta de ese carácter del prius de la realidad respecto de la inteligencia. Podría concluirse entonces, forzando algo la denominación, que la propuesta de Pintor es la de un "realismo extra-noológico" focalizado en el prius 
que lo real muestra en su análisis noológico. Sería un "prius-realismo".

Entrando en denominaciones de la filosofía realista de Zubiri más recientes, en Zubiri en la filosofía española del siglo XX. Diego Gracia (2017: 31-163) deja clara su postura: la filosofía de Zubiri es una filosofía transversalmente realista. $Y$ decimos "transversalmente realista" porque, para Diego Gracia, un cierto tipo de realismo atraviesa las siete fases filosóficas en las que divide la trayectoria intelectual de Zubiri. Cabe aclarar que esto es posible debido a que utiliza el término "realismo" en un sentido muy amplio, genérico, cuya base es que "todo ser humano tiene experiencia de realidad" (Gracia 2017: 68). Esta noción genérica de realismo, no obstante, es precisada en cada una de las siete fases con un calificativo que define el sentido que iba adoptando tal realismo. Por tanto, lo relevante para nuestro análisis está en el calificativo con el que define el realismo del Zubiri de Inteligencia sentiente, pues en esta última fase de su pensamiento sitúa el mismo Diego Gracia el punto arquimédico a partir del cual interpretar su pensamiento completo. Pues bien, denomina a esta séptima fase "realismo del 'estar' o de la actualidad" (Gracia 2017: 154). Tal denominación es justificada por la prioridad que da Zubiri a la noción de "actualidad" con respecto a la de "sustantividad", que tanto terreno había ganado en tanto que "de suyo" de las cosas reales. Gracia pone el foco de atención, por tanto, en la noción de actualidad, llegando a argumentar que "la 'realidad' no es otra cosa que 'actualidad"' (Gracia 2017: 160), pues hay realidades que pueden no tener sustantividad pero seguir estando presentes como reales en nuestra aprehensión (la conciencia, por ejemplo, no deja de ser real pero no es sustantiva). En este estar presente como reales consiste justamente la actualidad, elemento nuclear de la filosofía de Zubiri para Diego Gracia.

Otra interpretación diferenciada es la de Jesús Conill, quien califica la filosofía de Zubiri como un "realismo noérgico". Conill (1997: 183) se centra en el carácter noérgico con que la realidad se nos impone justamente porque desde tal noción Zubiri "radicalizó el análisis fenomenológico de los hechos hasta descubrir que la realidad está dada en un nivel previo a la conciencia". La noergia (fuerza de imposición) permite a Zubiri, superando la fenomenología desde sí misma, rescatar la realidad que había quedado como mero residuo hylético. $\mathrm{Y}$ justo en esto, transformando y corrigiendo radicalmente la fenomenología (aunque teniéndola como punto de referencia), es en lo que consiste la noología zubiriana: análisis del "factum primordial de la actualización noérgica de la realidad en la intelección" (Conill 2018: 279). La clave en la superación del idealismo y del realismo tradicional no está, por tanto, en el hecho de la actualización en general, sino en el carácter noérgico con que la realidad se actualiza en la aprehensión. Se pone el foco, por tanto, en el carácter de fuerza de lo real en el marco del análisis noológico.

Por último, puede incluirse también aquí la propuesta de Carlos Sierra de una "reología", un "nuevo realismo" o "realismo real" que, si bien no es estrictamente una interpretación de Zubiri, sí pone en juego elementos relevantes para delimitar el alcance de nuestra propuesta interpretativa. Sierra (2018) radicaliza la lectura que hemos analizado de Antonio Ferraz, pues entiende que aquella diferencia entre la "realidad" intraintelectiva y la "realidad-de" la cosa real nos pone ante "dos" tipos de realismo: un realismo de partida, la noología; y un realismo de llegada, la reología. Pues bien, si en el plano analítico el punto de partida es noológico, desde un punto de vista metafísico ha de afirmarse que "nunca hay solo realidad (entendida como formalidad) sino en la medida en que hay cosa-realidad" (Sierra 2020: 197). Realidad es siempre genitivamente de la cosa, de la res que está ahí presente a la inteligencia. Si bien el estudio de los actos intelectivos es velis nolis el punto de partida, ello no deja de lado la necesidad de un estudio de la cosa-realidad, el cual ha sido dejado de lado por los investigadores zubirianos que se han centrado tanto en la noología. A este estudio es al que denomina "reología" como forma de un "nuevo realismo" cuyo foco sea la realidad "no solo en tanto inteligida sino en tanto de suyo sustantiva, no como término del acto intelectivo sino como constitución física" (Sierra 2020: 198). Esta propuesta no pretende ser una interpretación de Zubiri, pues aunque es claramente heredera de su sistema de pensamiento deja claro que su objetivo no es limitarse a este sino continuar alguna de las vías que dejó abiertas. Claro está, las vías se han centrado precisamente en unos elementos y no en otros, siendo aquí los principales el análisis de sustantividades, la metafísica de la realidad y la relevancia de la cosa-realidad.

\section{2. "Estrategia comprehensiva": noología realista}

Definir la filosofía de Zubiri como una noología realista o como un realismo noológico es un modo convergente de precisar en qué sentido puede ser considerada su filosofía en el marco del realismo. La 
justificación de tal tesis se basa en la capacidad de la estrategia comprehensiva de incluir en su seno el conjunto de elementos específicos de las estrategias focalizadas. Veamos cómo.

\subsubsection{Integración de los elementos de las interpretaciones de "estrategia focalizada"}

Llevar a cabo, como nos proponía Antonio Ferraz, una investigación metafísica de lo que la realidad sea por sí misma, efectivamente, es posible desde la filosofía zubiriana; pero su filosofía no es únicamente esto. Ferraz (1987: 129) mismo es consciente de que es irrenunciable el punto de partida noológico: "la formalidad de realidad (...) nos sitúa en la línea de la actualidad, que es la radical, la fundamental, pues antes de poder afirmar cualquier relación entre cosas, estas tienen que estar físicamente presentes en la aprehensión intelectiva". La radicalidad del realismo zubiriano, por tanto, ha de situarse precisamente en lo que de noológico tiene, pues la raíz, en efecto, es que la realidad solo puede analizarse en tanto que actualizada en una inteligencia sentiente. Y como lo que pueda ofrecer la metafísica de la realidad de Zubiri pende formalmente del análisis de partida noológico, la denominación de "realismo radical" de Ferraz cae dentro de las redes de la noología realista, sin que ello obste para que las investigaciones metafísicas en las que ponía el foco tengan su relevancia teórica y puedan ser incluidas.

En el caso de Antonio Pintor cabe reconocer que el término prius es uno de los más polémicos por tratarse justamente de una de las nociones que establecen la interrelación entre análisis noológico del acto de intelección y realidad allende dicho acto. Prius es un rasgo que muestra lo real pero en el marco de su actualización intelectiva. Es clave, por tanto, para romper con el círculo de la conciencia inmanente. No cabe duda de que para Zubiri es un concepto primordial en tanto que engarza el momento de actualidad con la realidad: "la actualidad lo es de la realidad misma, y por tanto está fundada en la realidad intelectivamente aprehendida. Porque la formalidad de realidad es un prius de la cosa aprehendida respecto de su aprehensión" (Zubiri 1980: 146). El momento de fundación de la actualidad, hasta aquí llega Zubiri, está en ese prius con que la realidad queda como formalmente anterior. Pero ello no quiere decir que su punto de partida sobrepase los límites noológicos, es decir, independientemente del análisis de los actos intelectivos. Como llega a reconocer Pintor, "en la aprehensión misma la realidad aparece dada como un prius respecto a todo acto de actualización intelectiva" (Pintor 2006: 175). En tanto que dado en la aprehensión misma es por lo que está dada como un prius; y el análisis de cómo se da esa realidad en la aprehensión, de los actos intelectivos, es justamente en lo que consiste la noología. Por sí sola, quizá pueda ser una noción pobre, pero en tanto que realista, la noología integra los elementos aludidos que reclama Pintor para acogerse al tipo específico de prioridad que representa el prius. Se trata solamente de una prioridad "intra-intelectiva", pues Zubiri deja claro en la Introducción a Inteligencia y realidad que intelección y realidad (dicho de otro modo, realidad y saber de la realidad) son "estrictamente congéneres" (Zubiri 1980: 9-15, Nicolás 2011: 293-310).

Desde la propuesta noológico-realista así se entiende también, pues se asume que el punto de partida metódico es el análisis del acto intelectivo, en el cual se hace presente lo real bajo la forma de ser anterior al propio acto. Con ello se cumplen las propias exigencias que Pintor expone cuando denomina, con cautela, la filosofía de Zubiri como un realismo peculiar que encierra una noción de realidad formal. Las cosas ni son en sí mismas independientes del acto de intelección, ni tampoco son en sí mismas lo actualizado en la aprehensión:

"si finalmente debiese hablarse de 'realismo' zubiriano, habrá que tener presente que tal postura no se refiere de modo directo a una eventual realidad de las 'cosas en sí', sino a una formalidad intraintelectiva. Por ello, no tiene ningún fundamento sólido la reiterada interpretación que atribuye a Zubiri la idea de que las cosas son en sí tal como quedan en aprehensión, lo cual significaría una postura propia de un realismo dogmático que Zubiri jamás defendió" (Pintor 1994: 107).

Una vez reconocida y asumida la relevancia del concepto de prius, una vez precisado el significado y alcance que una noología puede tener, y una vez cumplidas las exigencias que ha de cumplir una lectura realista de Zubiri, se puede concluir que la noología realista contiene el elemento del prius de la realidad en que Pintor pone el foco.

En cuanto al realismo de la actualidad que Diego Gracia propone, no cabe duda de que la actualidad cobra un papel fundamental en la trilogía y, por ende, en la reinterpretación de toda su filosofía anterior. En efecto, "la esencia formal de la intelección sentiente es esta mera actualidad" (Zubiri 1980: 136) en tanto que constituye la unidad estructural del momento de intelección y del momento de impresión de la inteligencia sentiente. Para que un realismo de la actualidad tenga un sentido pleno ha de ser reconocido 
evidentemente como parte de un análisis noológico que involucra otras tantas nociones que, cada una con su papel propio, concurren en el acto intelectivo y en su despliegue analítico. Dado el incuestionable papel primordial de la actualidad en tanto que componente del análisis noológico, cabe incorporar el "realismo de la actualidad" en el marco de la "noología realista".

Algo similar ocurre con el realismo noérgico de Jesús Conill. Noergia es un aspecto constitutivo de lo real que aparece en el análisis del acto de aprehensión, y adquiere verdadera importancia en la noología zubiriana en tanto que es el momento intelectivo primario: "lo radical es un devenir de 'actualidad', un devenir que no es noético ni noemático sino noérgico" (Zubiri 1980: 64). Reconocida la relevancia de tal concepto, cabe advertir que todo momento noérgico adquiere su sentido y es comprensible en el marco noológico. Así lo asume Conill (2009: 226) cuando define la noergia dentro de una "analítica noológica de la facticidad noérgica de la realidad". En tanto que la noergia pende del análisis noológico, cabe concluir que la interpretación realista de la noología que estamos proponiendo integra como un momento suyo el "realismo noérgico".

En lo que respecta a la reología de Carlos Sierra, cabe aducir que siempre que se sitúe su punto de partida en el análisis de los actos intelectivos, y siempre que no sobrepase la co-generidad entre realidad y saber de la realidad, puede ser sistemáticamente vinculada al "realismo noológico", aunque analíticamente esté orientada hacia la dimensión metafísica del acto intelectivo. Es decir, el objetivo es el análisis de lo real actualizado noérgicamente en la intelección. Y, en efecto, este es el papel que Sierra (2020: 208) reclama para la reología, que "no quiere suplir la noología ni menospreciarla, lo que quiere es completar la metafísica cuyo momento de partida es el noológico". Noología y metafísica serían en este esquema modos complementarios y diferenciados de análisis de lo real. Son complementarios porque Zubiri está tan lejos de la idealista prioridad metodológica de la noología sobre la "ontología" como de la realista (dogmática) anterioridad de esta sobre el análisis del nous. Así entendido, la reología sería compatible con el realismo noológico, aunque este sea solamente su ineludible "momento de partida".

\subsubsection{Aportaciones y rendimiento de la interpretación noológico-realista}

En la diferencia entre las dos estrategias interpretativas ya se han dejado entrever las aportaciones de la interpretación noológico-realista, que resumimos a continuación.

El principal rendimiento que presenta la noología realista es, por su estrategia comprehensiva, su capacidad de integrar otras propuestas interpretativas enfocadas en elementos específicos de la filosofía de Zubiri. Ello implica, en primera instancia, el reconocimiento de la parte de verdad que a cada una de estas propuestas le corresponde. Cada una puede estar centrada en un determinado aspecto de la filosofía de Zubiri y no en otros, pero ello no impide que tales desarrollos sean compatibles dentro de un marco más amplio. La propuesta de la Noología realista proporciona ese marco. En segundo lugar, también implica la capacidad de ponerlas en relación en tanto que focalizadas en distintos momentos de la intelección, como partes de un todo. La noología realista o el realismo noológico aporta esa plataforma amplia que incorpora y comprehende las interpretaciones que se centran en elementos más específicos. La discusión acerca de qué aspecto tenga más o menos relevancia será, por tanto, un debate posterior. Pero el marco general será compartido: el de una filosofía de la realidad cuyo punto de partida es la noología. Esa es la amplia plataforma noológico-realista a partir de la cual puede darse una integración entre las diversas propuestas interpretativas realistas.

En segundo lugar, ante las múltiples y variadas formas de calificar el realismo de Zubiri que se han dado, la propuesta noológico-realista aporta cauces por los que sea viable cierta unidad interpretativa en torno a la denominación de la filosofía de Zubiri. Bien es cierto que aunque las interpretaciones focalizadas difieran en la denominación del tipo de realismo de Zubiri, el contenido de unas propuestas y otras se solapan y describen, en general, la filosofía de Zubiri de un modo unitario. La tarea de clarificación conceptual de los años posteriores a la publicación de Inteligencia sentiente contribuyó a evitar malentendidos y a describir con precisión las nociones originarias en las que se cimentaba la filosofía zubiriana. De ahí que las discusiones no se sitúen en la identificación de nociones relevantes como "actualidad", "noergia", "alteridad", "de suyo", "realidad", "aprehensión primordial de realidad", etc.; sino que la discusión se da en la prioridad que merece cada uno de estos conceptos con respecto a los otros. He aquí el origen de la variedad de adjetivos que se han propuesto para denominar el realismo de Zubiri. Pues bien, la propuesta noológico-realista, por tener como objetivo la comprehensión de las propuestas existentes, se presenta como una forma unitaria de interpretación que no agota ni absorbe las ya existentes, sino que las reúne bajo un mismo marco común: el de una noología que es realista, o lo que 
es lo mismo, el de un realismo que es noológico. Con lo cual, todos los argumentos que defienden que la filosofía de Zubiri sea un realismo podrían seguir defendiéndose, pero además les aporta una unidad que permite que los argumentos se apoyen los unos en los otros, haciendo la argumentación más consistente.

Por último, cabría señalar como aportación de la propuesta noológico-realista que logra minimizar la equivocidad en la denominación. En lo que respecta a las principales divergencias interpretativas en este artículo presentadas, la noología realista, en tanto que noológica, evita los malentendidos que entiendan a Zubiri como un realista ingenuo; pero también, en tanto que realista, afronta y rebate las sospechas idealistas. Con ello, se haría justicia a la filosofía de la realidad que ofrece Zubiri pero evitando, al asumir su crítica a los realismos, la acusación de realista dogmático o ingenuo en tanto que tal filosofía de la realidad tiene un punto de partida noológico. Cierta equivocidad, bien es cierto, nunca podrá suprimirse de modo absoluto, pero sí puede minimizarse con la propuesta presentada.

En cualquier caso, hay que reconocer que la originalidad del pensamiento zubiriano es difícilmente abarcable en una sola denominación. Por ello, al tomar como estrategia la búsqueda de una plataforma que sirva como unidad del conjunto de interpretaciones focalizadas en ciertos elementos concretos, nuestra propuesta pierde algo de especificidad pero gana en comprehensión. Es un coste que ha de asumirse en beneficio de las aportaciones que ofrece.

De otro lado, al acudir a una expresión relativamente general como Noología realista, capaz de integrar otras interpretaciones, se consolida una línea de interpretación en el ámbito específico del realismo. Lo cual, por un lado salva las críticas zubirianas a los realismos ingenuo y crítico, pero a la vez hace honor al papel determinante que lo real juega en toda la filosofía de Zubiri.

\section{Notas}

1. Transcripción propia de una grabación en la que Ellacuría habla sobre su interpretación de Zubiri. Audio disponible en la web Fundación X. Zubiri: https://www.zubiri.net/bienvenida/recursos-web/voceshistoricas/

2. Los argumentos que aquí se esgrimen se presentan como reconstrucción propia (no literal) de la discusión que Ellacuría mantuvo con Zubiri en el seminario Xavier Zubiri el día 13 de abril de 1978, audiograbación accesible al público (desde noviembre de 2020) que corrige y amplía partes de la transcripción publicada como apéndice al libro Escritos menores (2007). Audiograbación disponible en: https://www.zubiri.net/bienvenida/recursos-web/videos/dos-sesiones-del-seminario-xavier-zubiri/

\section{Bibliografía}

Conill, Jesús

1997 "La fenomenología en Zubiri", Pensamiento (Madrid), vol. 53, n² 206: 177-190.

2009 "Facticidad, intelección, noergia", Cuadernos salmantinos de filosofía (Salamanca), n. ${ }^{\circ}$ 36: 215-231.

2018 "Realismo noérgico y tragedia intelectual de Zubiri", Isegoría (Madrid), nº 58: 271-286.

Ellacuría, Ignacio

1990 Filosofía de la realidad histórica. San Salvador, UCA Editores.

Ferraz, Antonio

1987 Zubiri: el realismo radical. Madrid, Ediciones Pedagógicas, 1995.

2011 "La filosofía de la naturaleza", en Juan Antonio Nicolás (coord.), Guía Comares de Zubiri. Granada,

Editorial Comares: 351-378. 
González, Ángel

2015 "En el laberinto. La crisis de la razón filosófica en Husserl y Zubiri”, Pensamiento (Madrid), vol. 71, $\mathrm{n}^{\circ}$ 266: 309-352.

2020 “¿Realismo zubiriano? A propósito de un diálogo entre Ignacio Ellacuría y Xavier Zubiri”, Archivo Fundación Xavier Zubiri.

Gracia, Diego

1986 Voluntad de verdad. Para leer a Zubiri. Madrid, Triacastela, 2007.

2017 El poder de lo real. Leyendo a Zubiri. Madrid, Triacastela.

Nicolás, Juan Antonio

2011 "La teoría zubiriana de la verdad", en Guía Comares de Zubiri. Granada, Comares: 293-310.

2021 "La crítica de los realismos desde la noología realista zubiriana", en A. Pintor y otros (coord.), El valor de lo real. Homenaje a Diego Gracia. Madrid, Fundación Xavier Zubiri: 205-231.

Pintor, Antonio

1994 Realidad y verdad. Las bases de la filosofía de Zubiri. Salamanca, Publicaciones Universidad Pontifica de Salamanca.

1995a "Carta abierta al Dr. Wessell”, Diálogo Filosófico (Madrid), n 31: 73-77.

1995b "Intelectualismo e inteleccionismo", en Javier Muguerza y otros, Del sentido a la realidad. Estudios sobre la filosofía de Zubiri. Madrid, Trotta/Fundación Xavier Zubiri: 109-128.

2006 Nudos en la filosofía de Zubiri. Salamanca, Publicaciones Universidad Pontificia de Salamanca.

Sierra, Carlos

2018 "Noología y reología: el problema de los 'dos' realismos”, Seminario Xavier Zubiri (sesión 7 diciembre 2018).

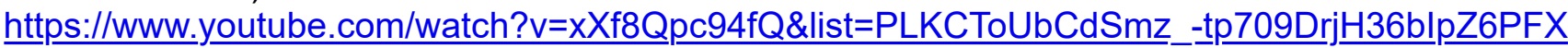

2020 “Reología, ¿en qué está la novedad?”, Devenires (Michoacán), nº 42: 193-211.

Wessell, Leonard P.

1999 "El 'de suyo' mismo es también 'algo'. Algo sobre la fundación idealista del realismo zubiriano", Estudios filosóficos (Valladolid), nº 137: 25-47.

Zubiri, Xavier

1942 Naturaleza, Historia, Dios. Madrid, Alianza Editorial/Fundación Xavier Zubiri, 1994.

1962 Sobre la esencia. Madrid, Alianza Editorial/Fundación Xavier Zubiri, 2008.

1978 “Dos sesiones del seminario Xavier Zubiri”, Fundación Xavier Zubiri.

https://www.zubiri.net/bienvenida/recursos-web/videos/dos-sesiones-del-seminario-xavier-zubiri/

1984 "Dos etapas", Revista de Occidente (Madrid), $\mathrm{n}^{\circ}$ 32: 43-50.

1980 Inteligencia sentiente, vol. I: Inteligencia y realidad. Madrid, Alianza Editorial/Fundación Xavier Zubiri, 1998.

1996 Espacio, tiempo y materia. Madrid, Alianza Editorial/Fundación Xavier Zubiri, 2008.

2001 Sobre la realidad. Madrid, Alianza Editorial/Fundación Xavier Zubiri.

2005 El hombre: lo real y lo irreal. Madrid, Alianza Editorial/Fundación Xavier Zubiri.

2007 Cursos universitarios I. Madrid, Alianza Editorial/Fundación Xavier Zubiri. 